\title{
Practice patterns and clinical significance of use of capsule endoscopy in suspected and established Crohn's disease
}

\author{
Yonghyun Kim, Seong Ran Jeon, Sang Myung Choi, Hyun Gun Kim, Tae Hee Lee, Jun-Hyung Cho, \\ Yunho Jung, Wan Jung Kim, Bong Min Ko, Jin-Oh Kim, Joon Sung Lee, Moon Sung Lee \\ Institute for Digestive Research, Digestive Disease Center, Soonchunhyang University College of Medicine, Seoul, Korea
}

\begin{abstract}
Background/Aims: Although the role of capsule endoscopy (CE) in Crohn's disease (CD) has expanded, CE is not used routinely for diagnosing and evaluating $\mathrm{CD}$ in Korea. We aimed to investigate current patterns of practice and evaluate the clinical significance of the use of CE in CD in Korean patients. Methods: Among 651 CE procedures performed for various indications, we retrospectively analyzed the medical records of patients who underwent CE in 57 cases of suspected CD (sCD) and 14 cases of established CD (eCD). Results: In the sCD group, CE was most commonly used for the initial diagnosis of CD (54.4\%). Capsule retention was found in only 1 patient in the eCD group $(1 / 71,1.4 \%)$. In the sCD group, $28.1 \%$ of patients were diagnosed with CD on the basis of CE findings; other diseases diagnosed included tuberculous enteritis (7.0\%), non-steroidal anti-inflammatory drug-induced enteropathy (5.3\%), and other enteritis (17.5\%). Only $11.5 \%$ of patients with eCD (14/122) underwent $\mathrm{CE}$. The indication for $\mathrm{CE}$ in the 14 patients with $\mathrm{eCD}$ was to assess disease extent and activity. The overall diagnostic yield of CE was $59.7 \%$. Therapeutic strategies were changed in $70.2 \%$ of patients in the sCD group and $50 \%$ of those in the eCD group based on CE findings. Conclusions: In clinical practice, CE was most commonly indicated for the initial diagnosis of CD and was not generally performed in patients with eCD. CE appears to be an effective diagnostic modality for evaluating sCD and is useful for determining therapeutic strategies for patients with sCD and those with eCD. (Intest Res 2017;15:467-474)
\end{abstract}

Key Words: Crohn disease; Capsule endoscopy; Indication; Therapeutic plan

\section{INTRODUCTION}

Crohn's disease (CD) is an IBD that can affect the entire gastrointestinal tract, the small bowel (SB) being the most commonly affected site. ${ }^{1}$ Previous studies on CD have shown SB involvement in approximately $70 \%$ of affected patients, ${ }^{2}$

Received May 30, 2016. Revised October 16, 2016.

Accepted October 26, 2016. Published online May 24, 2017

Correspondence to Seong Ran Jeon, Institute for Digestive Research,

Digestive Disease Center, Soonchunhyang University College of Medicine, 59

Daesagwan-ro, Yongsan-gu, Seoul 04401, Korea. Tel: +82-2-709-9202,

Fax: +82-2-709-9696, E-mail: 94jsr@hanmail.net

Co-Correspondence to Jin-Oh Kim, Institute for Digestive Research,

Digestive Disease Center, Soonchunhyang University College of Medicine, 59

Daesagwan-ro, Yongsan-gu, Seoul 04401, Korea. Tel: +82-2-709-9202,

Fax:+82-2-709-9696, E-mail: jokim@schmc.ac.kr

*This paper has two corresponding authors.

Financial support: This work was supported by Soonchunhyang University Research Fund. Conflict of interest: None. with the disease localized to the SB in one-third of patients with $\mathrm{CD}{ }^{3,4}$ According to a study of Korean patients with CD, the SB was affected in approximately $90 \%$ of patients with $\mathrm{CD} .{ }^{5}$ Localization of $\mathrm{CD}$ in the SB-and particularly if limited to this region-presents a diagnostic challenge, as conventional colonoscopy and small bowel follow-through (SBFT) are unable to directly visualize the SB. However, the introduction of SB diagnostic modalities such as capsule endoscopy (CE) and double-balloon enteroscopy have increased the rates of detection of SB CD. ${ }^{6,7} \mathrm{SB}$ assessment is currently considered a poor prognostic factor for long-term outcomes in $\mathrm{CD}^{8}$

CE can be utilized to assess various aspects of CD. It may provide confirmation of the diagnosis and assessment of the extent of disease in cases of suspected CD (sCD), while in established CD (eCD), it can be used to monitor disease activity, mucosal healing $(\mathrm{MH})$, and postsurgical recurrence. ${ }^{9}$

\footnotetext{
(c) Copyright 2017. Korean Association for the Study of Intestinal Diseases. All rights reserved.

This is an Open Access article distributed under the terms of the Creative Commons Attribution Non-Commercial License (http://creativecommons.org/licenses/by-nc/4.0)

which permits unrestricted non-commercial use, distribution, and reproduction in any medium, provided the original work is properly cited.
} 
Establishing a diagnosis of SB CD is among the primary indications for $\mathrm{CE}^{7}{ }^{7}$ However, in eCD, CE is primarily used for monitoring CD activity, a key factor to determine the appropriate therapeutic strategy, especially owing to the recently changed focus of CD treatment from symptom control to reducing inflammation and achieving $\mathrm{MH} .{ }^{10}$

The diagnostic yield of CE for CD varies from $28 \%$ to $71 \%{ }^{11-14}$ A meta-analysis comparing the diagnostic yield of CE for CD against that of other imaging modalities showed that CE is superior to CT enterography (CTE) ${ }^{12,15}$ Although the role of CE in CD has expanded significantly, CE is not routinely used for the diagnosis and evaluation of $\mathrm{CD}$ in Korean patients. We aimed to investigate current practice patterns and evaluate the clinical significance of the use of CE in $\mathrm{CD}$ in Korean patients.

\section{METHODS}

\section{Study Design and Patients}

Between March 2003 and June 2015, 651 CE procedures were performed for various indications. Patients were excluded from the analysis if they had other SB diseases such as infectious disease, ischemia, vasculitis, tumor, or lymphoma. Finally, we retrospectively analyzed the medical records of patients who underwent CE in 57 cases of sCD and 14 cases of eCD. CE was not indicated for patients in whom obstructive symptoms or obstructive lesions were observed on radiological studies. Among all patients undergoing CE, 74.7\% (53/71) underwent SBFT and/or abdominal CT for evaluating SB strictures. This study was approved by Soonchunhyang University Hospital Institutional Ethics Review Board (2015-07-025) and waived for informed consents.

\section{Definitions}

Criteria used to define SCD were the presence of at least 2 of the following: abdominal pain or diarrhea, iron deficiency anemia, elevated ESR or CRP levels, hypoalbuminemia, extraintestinal manifestations, and family history of IBD. eCD was defined as previously diagnosed cases of CD that fulfilled established diagnostic criteria (presence of symptoms and a combination of endoscopic, pathologic, radiologic, and/or laboratory abnormalities). ${ }^{16,17}$ Indications for CE were categorized as follows: (1) initial diagnosis, (2) differential diagnosis, (3) assessment of disease extent and activity, (4) assessment of MH, and (5) identification of postoperative recurrence. Performance of CE in patients with SCD who met the disease criteria was considered the "initial diagnosis" indication for CE. In cases in which evidence of CD, tuberculosis (TB), or other inflammatory diseases was observed in radiological findings obtained prior to $\mathrm{CE}$, the performance of CE indicated "differential diagnosis of CD." In the present study, the diagnostic criteria used to diagnose CD on the basis of the CE images obtained were the presence of $>3 \mathrm{SB}$ ulcerations (in the absence of history of NSAID ingestion) or $>10$ aphthous or erosive lesions showing either continuous or segment-like distribution. ${ }^{18,19}$ More frequently than $\mathrm{CD}$, TB presents a patulous ileocecal valve, transverse ulcers, pseudopolyps, or cicatricial change. TB was considered in cases wherein CE revealed these findings. ${ }^{20}$ NSAID-induced enteropathy was diagnosed when CE revealed lesions such as reddened folds, denuded areas, red spots, mucosal breaks, or diaphragmatic ulcers, with a history of NSAID ingestion. ${ }^{21}$ The phenotype was classified in accordance with the Montreal classification system. The final diagnosis was determined after integrating clinical manifestations, laboratory tests, and disease course based on CE findings. Conservative treatment included nil per os (NPO), total parenteral nutrition, transfusion, or iron replacement. Specific treatment included the addition or increased dosage of anti-inflammatory drugs, steroids, immunomodulators (IMs), or anti-TB medications.

\section{CE Procedure}

CE was performed using either the PillCam ${ }^{\mathrm{TM}} \mathrm{SB} 1 / \mathrm{SB} 2$ (Given Imaging, Yokneam, Israel) or the MiroCam ${ }^{\mathrm{TM}}$ (IntroMedic Co., Seoul, Korea). Prior to the procedure, patients underwent bowel preparation (using polyethylene glycol 1-2 L, Colyte ${ }^{\mathrm{TM}}$; Taejun Pharmacy, Seoul, Korea) and were kept NPO for at least 8 hours. Abdominal radiography was performed to confirm gastric retention of the capsule 2 hours after swallowing either the PillCam or the MiroCam. All images were reviewed by 2 board-certified endoscopists. The quality of CE images was classified as acceptable (excellent, good, or fair) or unacceptable (poor). ${ }^{22}$

\section{Statistical Analysis}

Statistical analysis was performed using PASW Statistics version 18.0 for Windows (SPSS Inc., Chicago, IL, USA). The results are presented as mean \pm SD or number (\%). Continuous variables were analyzed using a two-tailed Student $t$ test or Fisher exact test. Categorical variables were analyzed using the chi-square test. A $P$-value of 0.05 was considered 
statistically significant.

\section{RESULTS}

\section{Baseline Characteristics}

The mean ages of the patients in the $\mathrm{SCD}$ and $\mathrm{eCD}$ groups were $45.8 \pm 15.9$ and $37.4 \pm 17.0$ years, respectively. Analysis of sex showed that $61.4 \%$ of patients in the sCD group and $78.6 \%$ of patients in the eCD group were male. In both groups, CE was performed in two-thirds of patients within 2 years of diagnosis of $\mathrm{CD}$ (sCD [85.9\%] vs. eCD [64.2\%]). A higher percentage of patients in the SCD group had a positive history of administration of NSAIDs, anticoagulants, or antiplatelet agents than in the eCD group (21.0\% vs. $7.1 \%)$. At the time of CE, $71.4 \%$ of patients (10/14) in the eCD group were receiving treatment with only 5 -aminosalicylic acid (5ASA), and 28.6\% (4/14) were receiving treatment with 5-ASA and steroids. A history of abdominal surgery was more common in the eCD group than in the SCD group (1.8\% vs. $35.7 \%$, $P=0.001)$. No significant differences were observed between the sCD and eCD groups with regard to the baseline laboratory characteristics listed in Table 1.

\section{CE indication and CE-Related Data}

In the sCD group, the most common indication for CE for CD was initial diagnosis (54.4\%), followed by differential diagnosis (45.6\%). Twenty-five of 57 patients with sCD (43.8\%) presented with overt obscure gastrointestinal bleeding. Only $11.5 \%$ of patients in the eCD group (14/122) underwent CE. Although 3 of 14 patients with eCD received SB and/or colon resection prior to $\mathrm{CE}$ owing to $\mathrm{CD}$, all CEs in patients with eCD were performed for the assessment of disease activity. No significant differences were observed in the percentage of patients in the sCD and eCD groups with regard to the type of CE, quality of images, arrival rate of capsule at the cecum, and SB transit time. Capsule retention was only observed in 1 patient $(7.1 \%)$ in the eCD group. The capsule was removed endoscopically via double-balloon enteroscopy, and an IM was added to the patient's treatment regimen. Table 2 displays the CE-related data.

Table 1. Baseline Characteristics of Patients with Suspected CD and Those with Established CD

\begin{tabular}{|c|c|c|c|}
\hline Characteristic & sCD & eCD & $P$-value \\
\hline No. of patients & 57 & 14 & \\
\hline Age (yr) & $47(16-75)$ & $29(21-69)$ & \\
\hline Male sex & $35(61.4)$ & $11(78.6)$ & 0.351 \\
\hline Disease duration $<2$ yr & $49(85.9)$ & $9(64.2)$ & 1.000 \\
\hline Medication use $\mathrm{e}^{\mathrm{a}}$ & $12(21.0)$ & $1(7.1)$ & 0.439 \\
\hline History of abdominal surgery & $1(1.8)$ & $5(35.7)$ & 0.001 \\
\hline Appendicitis & 0 & 2 & \\
\hline Small bowel resection & 0 & 1 & \\
\hline Colon resection & 1 & 1 & \\
\hline Small bowel and colon resection & 0 & 1 & \\
\hline \multicolumn{4}{|l|}{ Laboratory test } \\
\hline Leukocyte $(/ \mu \mathrm{L})$ & $5,950(1,600-16,000)$ & $6,800(4,000-11,900)$ & 0.533 \\
\hline Hemoglobin (g/dL) & $10.3(5.0-15.0)$ & $10.6(7.0-15.0)$ & 0.557 \\
\hline Platelet $\left(10^{3} / \mu \mathrm{L}\right)$ & $253(105-463)$ & $279(174-523)$ & 0.202 \\
\hline $\mathrm{ESR}(\mathrm{mm} / \mathrm{h})$ & $16.5(1-116)$ & $13.5(2-49)$ & 0.190 \\
\hline $\mathrm{CRP}(\mathrm{mg} / \mathrm{dL})$ & $0.17(0-10.20)$ & $0.13(0.02-7.50)$ & 0.847 \\
\hline Albumin (g/dL) & $3.9(2.1-5.2)$ & $4.1(1.6-4.6)$ & 0.702 \\
\hline Concordance rate between CE and SBF & $7 / 19(36.8)$ & 1/3 (33.3) & 0.197 \\
\hline Concordance rate between $\mathrm{CE}$ and abdominal CT & $8 / 40(20.0)$ & 1/6 (16.7) & 0.775 \\
\hline
\end{tabular}

Values are presented as median (range) or number (\%).

${ }^{a}$ Medication use means history of administration of NSAIDs, anticoagulants, or antiplatelet agents. $s C D$, suspected $C D ; e C D$, established $C D ; C E$, capsule endoscopy; $S B F$, small bowel follow-through. 
Table 2. Capsule Endoscopy-Related Data for Patients with Suspected $\mathrm{CD}$ and Those with Established CD

\begin{tabular}{lccc}
\hline & $\begin{array}{c}\text { sCD } \\
(\mathbf{n = 5 7 )}\end{array}$ & $\begin{array}{c}\text { eCD } \\
(\mathbf{n}=\mathbf{1 4})\end{array}$ & P-value \\
\hline Type of CE & & & 0.084 \\
$\quad$ PillCam (SB1) & $25(43.9)$ & $10(71.4)$ & \\
$\quad$ PillCam (SB2) & $21(36.8)$ & $1(7.1)$ & \\
$\quad$ MiroCam & $11(19.3)$ & $3(21.4)$ & \\
Acceptable quality of images & $47(90.4)$ & $11(100.0)$ & 0.576 \\
Complete SB evaluation & $41(77.8)$ & $7(58.3)$ & 0.271 \\
Transit time (min) & $377 \pm 149$ & $310 \pm 118$ & 0.248 \\
CE retention & 0 & $1(7.1)$ & 0.197 \\
\hline
\end{tabular}

Values are presented as number (\%) or mean \pm SD.

sCD, suspected $C D$; eCD, established $C D$; $C E$, capsule endoscopy; $S B$, small bowel.

\section{CE Findings and Final Diagnosis}

In the sCD and eCD groups, the combined jejunal and ileal area represented the most common site of involvement (37.3\% and 53.8\%, respectively). Variable ulcerations were the most common findings in SCD (41.2\%) and eCD (57.1\%). Typical longitudinal ulcers were present in $23.5 \%$ and $14.3 \%$ of patients with sCD and eCD, respectively. The proportions of 14 patients with eCD with B1, B2, and B3 disease at diagnosis were $71.4 \%, 28.4 \%$, and $7.1 \%$, respectively. The proportions of patients with L1, L2, L3, L4, and L3+L4 disease were $28.6 \%, 28.6 \%, 14.3 \%, 7.1 \%$, and $21.4 \%$, respectively. Following CE, the location of CD was modified in $64.2 \%$ of patients (from $\mathrm{L} 1$ to $\mathrm{L} 1+\mathrm{L} 4, \mathrm{n}=4$; from $\mathrm{L} 2$ to $\mathrm{L} 2+\mathrm{L} 4, \mathrm{n}=3$; from $\mathrm{L} 3$ to $\mathrm{L} 3+\mathrm{L} 4, \mathrm{n}=2$ ). The concordance rates between $\mathrm{CE}$ and SBFT/abdominal CT were $36.8 \% / 20.0 \%$ and $33.3 \% / 16.7 \%$ in the sCD and eCD groups, respectively; these findings were not significant. Table 3 summarizes the endoscopic findings including location of disease.

Of the 57 patients with sCD, 28.1\% (16/57) were diagnosed with CD on the basis of CE findings; other diagnoses included tuberculous enteritis, NSAID-induced enteropathy, and other enteritis (Fig. 1), which were identified in $7.0 \%$, $5.3 \%$, and $17.5 \%$ of patients, respectively (Fig. 2). The overall diagnostic yield of CE was $59.7 \%$ (34/57).

\section{Treatment and Adjustment of Therapeutic Strategies}

The majority of patients in the sCD group (70.2\%) were treated conservatively, while specific medications were initiated in 28.1\% ( $\mathrm{n}=14,5$-ASA; $\mathrm{n}=1,5$-ASA and steroid;
Table 3. Endoscopic Findings and Location of Disease Based on Capsule Endoscopy in Patients with Suspected CD and Those with Established CD

\begin{tabular}{|c|c|c|c|}
\hline & $\begin{array}{c}s C D \\
(n=57)\end{array}$ & $\begin{array}{c}\text { eCD } \\
(n=14)\end{array}$ & $P$-value \\
\hline Site of involvement ${ }^{a}$ & & & 0.662 \\
\hline Jejunum & $12(23.5)$ & $2(15.4)$ & \\
\hline Ileum & 18 (35.3) & $4(30.8)$ & \\
\hline Jejunum+ileum & $19(37.3)$ & $7(53.8)$ & \\
\hline Duodenum & $2(3.9)$ & 0 & \\
\hline Type of injury & & & 0.524 \\
\hline Normal & 0 & $2(14.3)$ & \\
\hline Aphthous ulcer & $2(11.8)$ & $1(7.1)$ & \\
\hline Longitudinal ulcer & $4(23.5)$ & $2(14.3)$ & \\
\hline Cobblestone appearance & 0 & 0 & \\
\hline Inflammatory polyp & $1(5.9)$ & 0 & \\
\hline Fistula & 0 & 0 & \\
\hline Variable ulcer & $7(41.2)$ & $8(57.1)^{b}$ & \\
\hline Variable ulcer+stricture & $2(11.8)$ & $1(7.1)$ & \\
\hline Variable ulcer+inflammatory polyp & $1(5.9)$ & 0 & \\
\hline
\end{tabular}

Values are presented as number (\%).

${ }^{a}$ Regardless of complete $\mathrm{SB}$ evaluation of $\mathrm{CE}$, the sites of observed lesions are described.

${ }^{b}$ In CE findings, 2 patients who received surgery after CE showed variable ulcers.

sCD, suspected $C D$; eCD, established $C D$.

$\mathrm{n}=1$, anti-TB medication), and potentially disease-causing drugs (NSAIDs) were terminated for $1.8 \%$ of patients. In the eCD group, therapy was retained for $57.1 \%$ of patients $(n=3$, 5-ASA) or specific medication was added and/or increased ( $\mathrm{n}=4$, addition of steroid; $\mathrm{n}=1$, dose increase of 5 -ASA and addition of steroid), while $14.2 \%$ of patients were referred for surgery owing to obstructive symptoms following CE. Nevertheless, there were no dominant obstructive lesions on SBFT. The performance of surgery after CE was not associated with CE retention in any case. The final pathology revealed chronic transmural inflammation with granuloma, consistent with CD. Therapeutic strategies were changed for $70.2 \%$ of patients (40/57) in the sCD group and $50 \%$ of patients (7/14) in the eCD group on the basis of CE findings. Treatment results are summarized in Table 4.

\section{DISCUSSION}

We investigated practice patterns of CE use in Korea and the clinical impact of CE in patients with CD and arrived at 

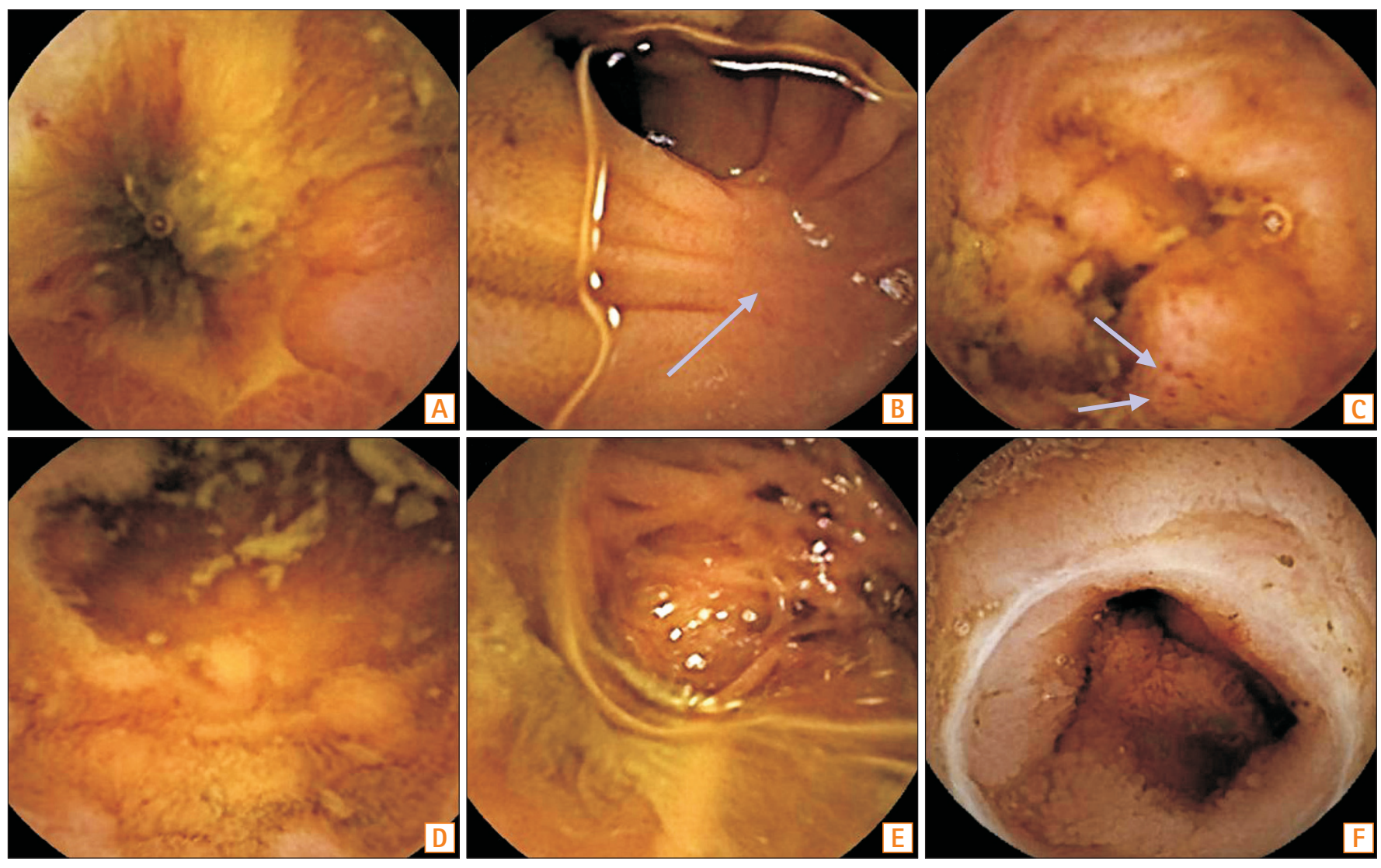

Fig. 1. Endoscopic findings of small bowel diseases. Capsule endoscopy (CE) images of CD show (A) ulcerations with luminal stricture, (B) a longitudinal ulcer scar (arrow), (C) luminal stricture with pseudopolyps and red spots (arrows), and (D) nodular lymphoid hyperplasia. CE images of intestinal tuberculosis and NSAID-induced enteropathy reveal (E) cicatricial change and (F) diaphragm-like strictures, respectively.

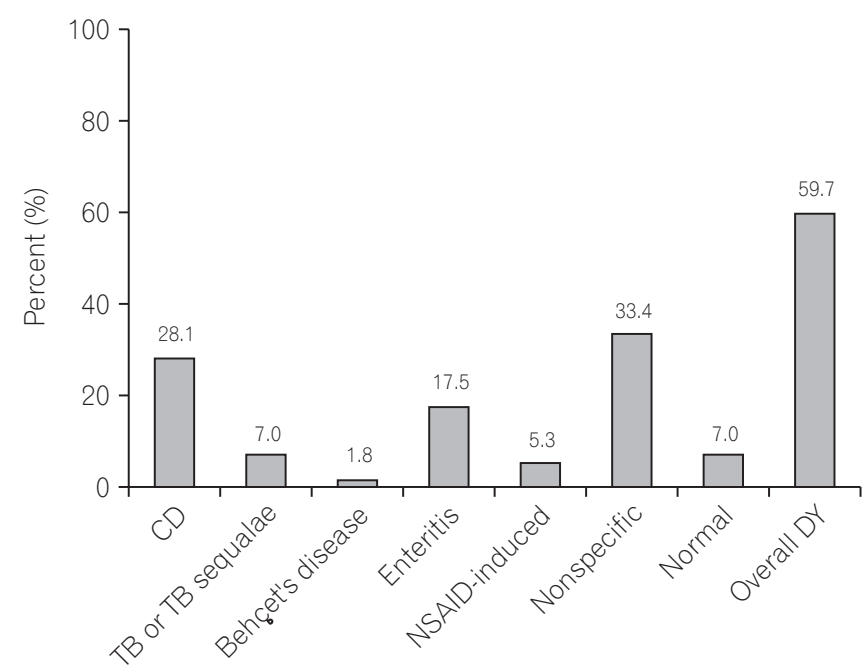

Fig. 2. Final diagnosis in suspected CD group. TB, tuberculosis; DY, diagnostic yield.

3 main conclusions. First, in actual practice, we found that generally, CE was not performed for patients with eCD. Second, approximately one-fourth of patients with sCD were
Table 4. Treatment Modalities and Therapeutic Plan Adjustment for Patients with Suspected CD and Those with Established CD

\begin{tabular}{lcc}
\hline & sCD ( $\mathbf{n = 5 7 )}$ & eCD $(\mathbf{n = 1 4 )}$ \\
\hline Treatment modality & & \\
Conservative treatment & $40(70.2)$ & $1(28.6)$ \\
Specific medication & $16(28.1)$ & $8(57.1)$ \\
Maintain & 0 & 3 \\
Add & 16 & 5 \\
Drug discontinuation & $1(1.8)$ & 0 \\
Operation & 0 & $2(14.2)$ \\
Therapeutic plan adjustment & $40 / 57(70.2)$ & $7 / 14(50.0)$ \\
\hline
\end{tabular}

Values are presented as number (\%).

sCD, suspected $C D$; $e C D$, established $C D$.

diagnosed with CD on the basis of CE findings. Third, therapeutic strategies were changed in $>50 \%$ of patients with sCD or eCD based on the results of CE.

In Korea, the incidence and prevalence of $\mathrm{CD}$ are increasing rapidly. ${ }^{5,23}$ At the time of initial diagnosis, two-thirds of 
CD cases involve the SB, and up to one-third of patients have lesions limited to the $\mathrm{SB}^{24,25}$ As symptoms are usually nonspecific, the location of lesions in $\mathrm{CD}$ is very difficult to ascertain clinically. On diagnosing CD, it is important to ascertain the involvement of the SB and to evaluate and characterize any existing SB lesions. The main advantage of CE compared to other radiologic modalities such as SBFT, $\mathrm{CT}$, and MRI is its ability to directly visualize the SB mucosa. Therefore, for patients with sCD, CE is used for diagnostic purposes because it distinguishes CD from other diseases such as intestinal TB and clearly delineates the extent and activity of disease. ${ }^{26}$

In the present study, the most common indication for CE in patients with $\mathrm{CD}$ was to diagnose $\mathrm{CD}$. In a meta-analysis comparing CE with SBFT, CTE, and MR enterography (MRE) in sCD, although there was no significant difference in diagnostic yield between CE and MRE (weighted incremental yield $[\mathrm{IY}]=7 \%$, CE vs. MRE $50 \%$ vs. $43 \%$ ), the weighted IY of CE was significantly superior to that of SBFT (weighted IY $=32 \%$, CE vs. SBFT $52 \%$ vs. $16 \%$ ) and CTE (weighted $\mathrm{IY}=47 \%, 68 \%$ vs. $21 \%){ }^{16}$ The diagnostic yield of CE in patients with sCD ranges from $19 \%$ to $77 \%{ }^{27-29}$ In the current study, the overall diagnostic yield in the SCD group was $59.7 \%$, similar to that reported in a previous systematic review. ${ }^{30}$ $\mathrm{CE}$ alone was able to diagnose $\mathrm{CD}$ in more than one-fourth of the patients with SCD (28.1\%); most of the other patients in the sCD group had other causes of enteritis including TB. The potential usefulness of CE in patients with SCD should be emphasized, as the diagnosis of up to two-thirds of the patients in the sCD group was confirmed following CE, which enabled the institution of appropriate management.

In the present study, only $\sim 10 \%$ of the total group of patients with eCD underwent CE to assess disease extent and activity. In clinical practice, we can deduce that CE is not generally performed for the assessment of disease extent and activity, $\mathrm{MH}$, or postoperative recurrence in patients with eCD. According to a previous study to assess MH using the Capsule Endoscopy Crohn's Disease Activity Index (CECDAI) in patients with SB CD beginning treatment with biologics or IMs, up to $30 \%$ of patients showed MH at assessment 12 weeks after the initiation of treatment. ${ }^{31}$ In a recent study utilizing the Lewis score, only $15.4 \%$ of patients in clinical remission had actually achieved $\mathrm{MH}$ on assessment by $\mathrm{CE}$, while postoperative recurrence of $\mathrm{CD}$ was detected in up to $70 \%$ of patients between 6 months to 1 year after ileocolonic resection. ${ }^{32}$ Severe endoscopic recurrence can be used as a surrogate marker of future clinical recurrence. ${ }^{33} \mathrm{Al}-$ though MH is currently regarded as an important treatment strategy for patients with $\mathrm{CD}$, data regarding the use of $\mathrm{CE}$ to evaluate $\mathrm{MH}$ as an indicator of treatment efficacy is limited to Western countries. ${ }^{26,31}$

In the current study, we also found that CE was not performed for the assessment of MH or postoperative recurrence in patients with eCD, possibly owing to the risk of capsule retention, as it is relatively common for patients with eCD to have SB strictures, which are often considered a contraindication to CE. ${ }^{15,34}$ Therefore, the risk of capsule retention is one of the important factors limiting the use of $\mathrm{CE}$ in $\mathrm{eCD}$. The risk of capsule retention was reported to be as high as $13 \%$ in early studies; however, a pooled retention rate of $2.6 \%$ was reported in a recent study. ${ }^{30}$ According to a recent guideline for $\mathrm{CE}$ in $\mathrm{CD},{ }^{34} \mathrm{SB}$ radiological examination or patency capsule is recommended before CE for the evaluation of patients with eCD. However, not all patients with eCD could undergo SB radiologic examinations in the present study because some patients were enrolled at the time of their initial experience of CE in Korea. Nevertheless, we observed a lower percentage of capsule retention (1.4\%) compared to that in the aforementioned studies. The capsule was removed endoscopically, and the patient's treatment regimen was changed. These findings demonstrate that capsule retention does not always require surgical management, as the capsule can be removed endoscopically, and the disease can subsequently be managed using steroids, IM, or antitumor necrosis factor agents. Therefore, although capsule retention should be avoided, we believe that it may actually lead to appropriate treatment by allowing for localization of the culprit lesion.

CE can play an important role in aiding decision-making regarding therapy in patients with $\mathrm{CD}$. According to a previous study, CE findings resulted in altered management plans for $90 \%$ of patients with sCD and $73 \%$ of patients with eCD. ${ }^{25}$ However, another study reported that a change in treatment was recommended in $52.3 \%$ of patients on the basis of CE findings. ${ }^{8}$ In the present study, we found that therapeutic strategies for $70.2 \%$ of patients in the sCD group were modified on the basis of CE findings; in the eCD group, $57.1 \%$ of patients continued current medications or had a specific medication added. Overall, the results of CE resulted in alterations to the therapeutic plans of $>50 \%$ of patients in both the $\mathrm{SCD}$ and eCD groups.

The present study has several limitations. First, this study was a retrospective analysis and, as a single-center study, had a relatively small patient number. Second, a selection bias may have occurred because the assessment of patients with sCD and eCD was limited to those undergoing CE, 
which could limit the strength of our conclusions. Third, although previous studies have described CE criteria for the diagnosis of CD (which we adapted for our study), diagnostic criteria for CE in patients with sCD remain unclear and subjective. It is difficult to distinguish TB or NSAID-induced enteropathy from $\mathrm{CD}$ because each of these can exhibit various inflammatory lesions and/or ulcers during CE. However, we attempted to perform the diagnoses as accurately as possible after integrating clinical manifestations, laboratory tests, and disease course based on CE findings. Prospective, multicenter studies are needed to more objectively determine CE-based diagnostic criteria for CD. Despite these limitations, we believe that the present study is valuable because it provides an analysis of the current practice patterns of CE use in Korea and highlights the scope of the expanded indications for the use of $\mathrm{CE}$ in the management of $\mathrm{CD}$ and the clinical significance of CE findings for patients with CD.

In conclusion, the most common indication for $\mathrm{CE}$ in $\mathrm{CD}$ was for the initial diagnosis, and CE was not generally performed in patients with eCD in clinical practice. CE appears to be an effective diagnostic modality for the evaluation of sCD, as well as a useful tool in the determination of therapeutic strategies for patients with SCD and those with eCD.

\section{REFERENCES}

1. Kornbluth A, Colombel JF, Leighton JA, Loftus E; ICCE. ICCE consensus for inflammatory bowel disease. Endoscopy 2005;37:1051-1054.

2. Louis E, Collard A, Oger AF, Degroote E, Aboul Nasr El Yafi FA, Belaiche J. Behaviour of Crohn's disease according to the Vienna classification: changing pattern over the course of the disease. Gut 2001;49:777-782.

3. Cosnes J, Gower-Rousseau C, Seksik P, Cortot A. Epidemiology and natural history of inflammatory bowel diseases. Gastroenterology 2011;140:1785-1794.

4. ASGE Technology Committee, Wang A, Banerjee S, et al. Wireless capsule endoscopy. Gastrointest Endosc 2013;78:805-815.

5. Yang SK, Yun S, Kim JH, et al. Epidemiology of inflammatory bowel disease in the Songpa-Kangdong district, Seoul, Korea, 1986-2005: a KASID study. Inflamm Bowel Dis 2008;14:542549.

6. Carter D, Eliakim R. Current role of endoscopy in inflammatory bowel disease diagnosis and management. Curr Opin Gastroenterol 2014;30:370-377.
7. Kopylov U, Nemeth A, Koulaouzidis A, et al. Small bowel capsule endoscopy in the management of established Crohn's disease: clinical impact, safety, and correlation with inflammatory biomarkers. Inflamm Bowel Dis 2015;21:93-100.

8. Lazarev M, Huang C, Bitton A, et al. Relationship between proximal Crohn's disease location and disease behavior and surgery: a cross-sectional study of the IBD Genetics Consortium. Am J Gastroenterol 2013;108:106-112.

9. Kim M, Jang HJ. The role of small bowel endoscopy in small bowel Crohn's disease: when and how? Intest Res 2016;14:211217.

10. Kopylov U, Yablecovitch D, Lahat A, et al. Detection of small bowel mucosal healing and deep remission in patients with known small bowel Crohn's disease using biomarkers, capsule endoscopy, and imaging. Am J Gastroenterol 2015;110:1316-1323.

11. Marmo R, Rotondano G, Piscopo R, et al. Capsule endoscopy versus enteroclysis in the detection of small-bowel involvement in Crohn's disease: a prospective trial. Clin Gastroenterol Hepatol 2005;3:772-776.

12. Triester SL, Leighton JA, Leontiadis GI, et al. A meta-analysis of the yield of capsule endoscopy compared to other diagnostic modalities in patients with non-stricturing small bowel Crohn's disease. Am J Gastroenterol 2006;101:954-964.

13. Solem CA, Loftus EV Jr, Fletcher JG, et al. Small-bowel imaging in Crohn's disease: a prospective, blinded, 4-way comparison trial. Gastrointest Endosc 2008;68:255-266.

14. Esaki M, Matsumoto T, Watanabe K, et al. Use of capsule endoscopy in patients with Crohn's disease in Japan: a multicenter survey. J Gastroenterol Hepatol 2014;29:96-101.

15. Dionisio PM, Gurudu SR, Leighton JA, et al. Capsule endoscopy has a significantly higher diagnostic yield in patients with suspected and established small-bowel Crohn's disease: a metaanalysis. Am J Gastroenterol 2010;105:1240-1248.

16. Van Assche G, Dignass A, Panes J, et al. The second European evidence-based consensus on the diagnosis and management of Crohn's disease: definitions and diagnosis. J Crohns Colitis 2010;4:7-27.

17. Yao T, Matsui T, Hiwatashi N. Crohn's disease in Japan: diagnostic criteria and epidemiology. Dis Colon Rectum 2000;43(10 Suppl):S85-S93.

18. Gay GJ, Delmotte JS. Enteroscopy in small intestinal inflammatory diseases. Gastrointest Endosc Clin N Am 1999;9:115-123.

19. Mehdizadeh S, Chen GC, Barkodar L, et al. Capsule endoscopy in patients with Crohn's disease: diagnostic yield and safety. Gastrointest Endosc 2010;71:121-127.

20. Lee YJ, Yang SK, Byeon JS, et al. Analysis of colonoscopic findings in the differential diagnosis between intestinal tuberculosis and Crohn's disease. Endoscopy 2006;38:592-597. 
21. Gay G, Delvaux M, Frederic M. Capsule endoscopy in non-steroidal anti-inflammatory drugs-enteropathy and miscellaneous, rare intestinal diseases. World J Gastroenterol 2008;14:52375244.

22. Pons Beltrán V, González Suárez B, González Asanza C, et al. Evaluation of different bowel preparations for small bowel capsule endoscopy: a prospective, randomized, controlled study. Dig Dis Sci 2011;56:2900-2905.

23. Rameshshanker R, Arebi N. Endoscopy in inflammatory bowel disease when and why. World J Gastrointest Endosc 2012;4:201211.

24. Ng WK, Wong SH, Ng SC. Changing epidemiological trends of inflammatory bowel disease in Asia. Intest Res 2016;14:111119.

25. Luján-Sanchis M, Sanchis-Artero L, Suárez-Callol P, MedinaChuliá E. Indications of capsule endoscopy in Crohn's disease. Rev Esp Enferm Dig 2014;106:37-44.

26. Hudesman D, Mazurek J, Swaminath A. Capsule endoscopy in Crohn's disease: are we seeing any better? World J Gastroenterol 2014;20:13044-13051.

27. Eliakim R, Suissa A, Yassin K, Katz D, Fischer D. Wireless capsule video endoscopy compared to barium follow-through and computerised tomography in patients with suspected Crohn's disease: final report. Dig Liver Dis 2004;36:519-522.
28. Chong AK, Taylor A, Miller A, Hennessy O, Connell W, Desmond P. Capsule endoscopy vs. push enteroscopy and enteroclysis in suspected small-bowel Crohn's disease. Gastrointest Endosc 2005;61:255-261.

29. Efthymiou A, Viazis N, Vlachogiannakos J, et al. Wireless capsule endoscopy versus enteroclysis in the diagnosis of small-bowel Crohn's disease. Eur J Gastroenterol Hepatol 2009;21:866-871.

30. Liao Z, Gao R, Xu C, Li ZS. Indications and detection, completion, and retention rates of small-bowel capsule endoscopy: a systematic review. Gastrointest Endosc 2010;71:280-286.

31. Hall B, Holleran G, Chin JL, et al. A prospective 52 week mucosal healing assessment of small bowel Crohn's disease as detected by capsule endoscopy. J Crohns Colitis 2014;8:16011609.

32. Pons Beltrán V, Nos P, Bastida G, et al. Evaluation of postsurgical recurrence in Crohn's disease: a new indication for capsule endoscopy? Gastrointest Endosc 2007;66:533-540.

33. Vaughn BP, Moss AC. Prevention of post-operative recurrence of Crohn's disease. World J Gastroenterol 2014;20:1147-1154.

34. Park SK, Ye BD, Kim KO, et al. Guidelines for video capsule endoscopy: emphasis on Crohn's disease. Clin Endosc 2015;48:128-135. 